University of Nebraska - Lincoln

DigitalCommons@University of Nebraska - Lincoln

\title{
Semantic 3D CAD and Its Applications in Construction Industry - An Outlook of Construction Data Visualization
}

Zhigang Shen

University of Nebraska - Lincoln, shen@unl.edu

Raja R. A. Issa

University of Florida, raymond-issa@ufl.edu

Linxia Gu

South Dakota School of Mines and Technology, gul@fit.edu

Follow this and additional works at: https://digitalcommons.unl.edu/constructionmgmt

Part of the Construction Engineering and Management Commons

Shen, Zhigang; Issa, Raja R. A.; and Gu, Linxia, "Semantic 3D CAD and Its Applications in Construction Industry - An Outlook of Construction Data Visualization" (2007). Papers in Construction Management. 2. https://digitalcommons.unl.edu/constructionmgmt/2

This Article is brought to you for free and open access by the Construction Systems at DigitalCommons@University of Nebraska - Lincoln. It has been accepted for inclusion in Papers in Construction Management by an authorized administrator of DigitalCommons@University of Nebraska - Lincoln. 


\title{
Semantic 3D CAD and Its Applications in Construction Industry - An Outlook of Construction Data Visualization
}

\author{
Zhigang Shen ${ }^{1}$, Raja R.A. Issa ${ }^{2}$, and Linxia $\mathrm{Gu}^{3}$ \\ 1. University of Nebraska-Lincoln, Lincoln, Nebraska, USA; zshen2@unl.edu \\ 2. University of Florida, Gainesville, Florida, USA; raymond-issa@ufl.edu \\ 3. South Dakota School of Mines and Technology, Rapid City, South Dakota, USA; \\ linxia.gu@sdsmt.edu
}

\begin{abstract}
In response to the need of using electronic design data directly in construction management applications, many CAD developers have started implementing semantic data models in their CAD products using industry foundation classes (IFCs). While helpful, these semantic CAD applications have limitations when used in actual construction practices. The case studies in the thesis indicated that: 1) the semantics of the current data model (IFC as an example) is not rich enough to cover the richer details of the real trade practices; 2 ) the current implementation of the semantic data model lacks the mechanism to provide multiple trades views at various detailed levels. This paper also provided suggestions for the future development of semantic data model of construction industry.
\end{abstract}

Keywords: 3D CAD, IFC, Semantic, Data Visualization, Construction.

\section{Introduction}

As a major source of construction project data, CAD applications have traditionally been used as a drafting tool in the AEC industry, instead of as an integrated design information database for supporting production activities. As the result, information retrieval from design documents remains a manual process even though most design documents are in electronic format. This situation is one of the important factors that discourage contractors from using CAD in their operations (Figure 1).

A construction manager usually needs to coordinate many subcontractors, architects and engineers. In addition, frequent design changes are typical in the construction project. Thus, manually searching for design data and updating becomes a heavy burden for the project manager. In recent years the development of BIM (Building Information Model) started to address the existing barriers, which prevent 3D CAD application in construction industry.

The intention of BIM is to integrate the visualization capacity of the 3D CAD with the construction information data to allow construction managers to digi- 


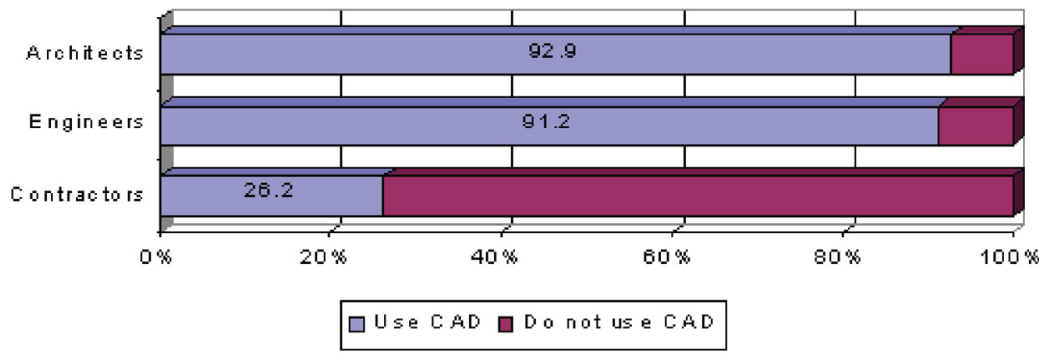

Figure 1. CAD usage in AEC industry [7]

tally retrieve and analyze design data directly from the CAD application. Some parametric CAD products [2] [3] incorporated IFC [4] product models in their internal data structure, which allowed these CAD applications to export semantically rich IFC data for reuse by other third-party application. These parametric AEC CAD applications not only allow designers to do quick 3D conceptual designs but they are also able to do quantity survey automatically.

Figure 2 illustrates the differences between the traditional geometric 3D CAD model and the parametric semantic 3D model. Figure 3 shows the differences of the internal data structure between the regular graphic-based CAD application and the IFC based CAD application. On top of the raw geometry data, the IFC model adds many construction semantic parameters, which intend to provide construction applications with a platform of semantically consistency.

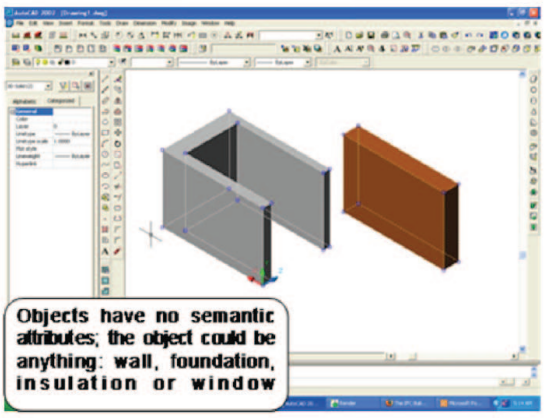

In geometric data model (AutocaD 2002)

The Object Alfributes are, Object ID, Points (x,y,z) coordinates, Line types, Direction of the object, tine Weight, Line Color, and etc.

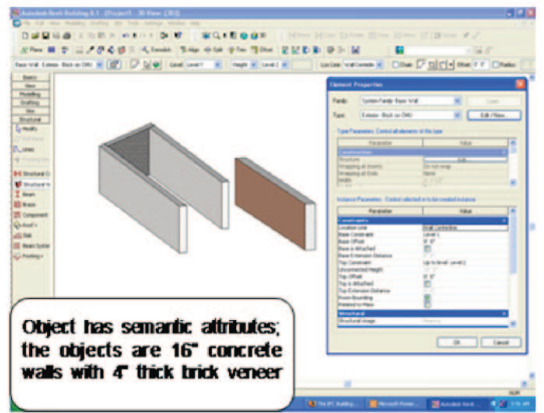

In perametule-semantic data model (Autodesk Rivet:) The Object Afrbutes are; Object ID, Wall type and composition, Material type, thickness, Volume, Surface area, Room bounding, and elc.

Figure 2. Attributes of geometric data model vs. parametric-semantic data model 


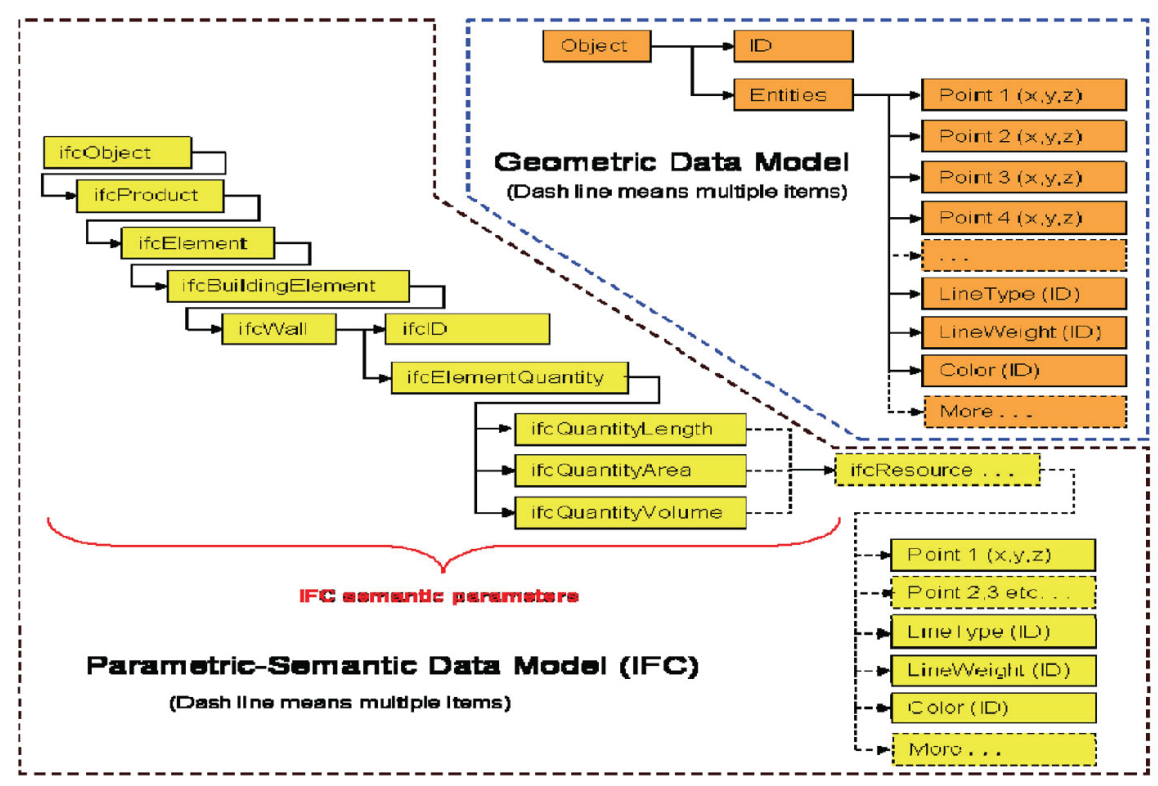

Figure 3. The data structure of geometric data model vs. parametric-semantic data model

\section{Limitations of Using IFC 3D CAD Application in Construction Quantity Survey}

Cost estimates are crucial for contractors to find out expected project cost, to create their budget and to evaluate the impact of the design changes. Because cost estimating is a quite time-consuming task many tools were developed to help the estimator to get the job done quicker. Those tools range from manually using color markers to using digitizing boards, to on-screen digitizing and to the latest CAD-based automatic estimating software.

In recent years, the IFC product-process model [4] has become more mature and was implemented by a few CAD vendors and construction software vendors. A few software applications implementing the IFC model have shown the capability to provide material quantities based on the CAD design documents. While helpful, the CAD based estimating applications are limited by the IFC semantic data model when used in calculating detailed quantities. The major limitation is that the current IFC model is not semantically rich enough to cover all the construction process data and job conditions.

The detailed construction estimate includes quantities that are much more complex than just simple material quantities. Many quantitative values depend on the construction process/construction methods and the very specific job conditions. In the current IFC model the process data structure is quite limited.

There are numerous construction methods and products and each construction method will have its own domain-specific views to the data model. When further considering the broad scope, uniqueness and the complexity of the construction 
project, it is very unlikely, as many researchers agree, that the single IFC model can cover all the construction aspects needed for supporting detailed estimates [5] [6].

\section{Concepts of Product/Procurement Quantity (PPQ) and Process Quantity (PCQ) in Construction Quantity Survey}

In order to further discuss the existing problems in the current CAD based estimating applications, it is necessary to first clarify the concept of quantities in the detailed estimating practice. The job quantities and cost are always the focal points of construction management throughout the project. The construction manager obtains physical job quantities and design features from the design documents. The construction manager comes up with the unit cost for this particular quantity amount based on the specific design feature and the applied construction methods. The specific cost of a specific portion of the project is calculated by multiplying the specific physical quantities and the unit cost. The overall project cost is the summation of the costs of each piece of the different specific features.

Project quantity is an over-generalized term when we consider detailed estimates. Project quantities can be further divided into Product/Procurement Quantities (PPQ) and Process.

Quantities (PCQ) and their corresponding costs are Product/Procurement Cost (PPC) and Process Cost (PCC).

The PPQ, as implied in its name, refers to physical material quantities, which will become part of the final building product when the project is completed. The PPQ, which includes the bill of materials, is often used for procurement. The PPQ are contained in the design documents and are relatively stable over the overall project duration. Since the material costs are relatively stable and will not vary much from job to job, both PPQ and PPC can be considered as static, as long as there is no significant design change.

On the other hand, PCQ refers to quantities that are closely-related to the construction methods, sequence and job conditions. PCQ differs significantly from one company to another, from construction method to construction method, even for the exact same project.

A particular PCQ depends on the particular construction method, the particular labor skills, the particular construction sequence and many other job conditions. For example, the formwork quantity of a concrete wall, which by definition is included in the PCQ, varies significantly between the cast-in-place method and the pre-cast method. Not only does the PCQ depend on the particular job condition, but the unit price of PCQ also depends on the particular job conditions. For example, the unit price of painting a dark wall color will cost more than the unit price of painting a light wall color.

\subsection{The PCQ Case Example}

To further explain the concepts of PCQ and PPQ, a simple case example of brick veneer is presented in this section to illustrate how construction methods and trade knowledge affect the detailed quantity estimating. Figure 1-7 shows a tilt-up concrete wall with brick veneer that is to be built as a retail building en- 


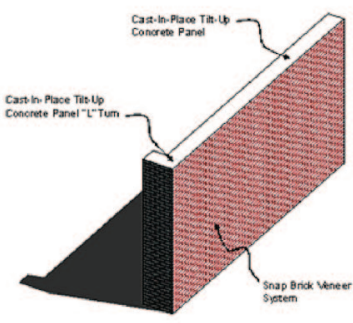

(a)

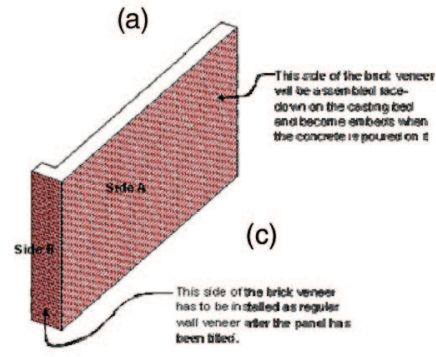

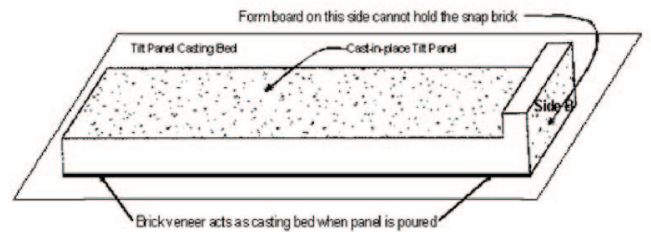

(b)

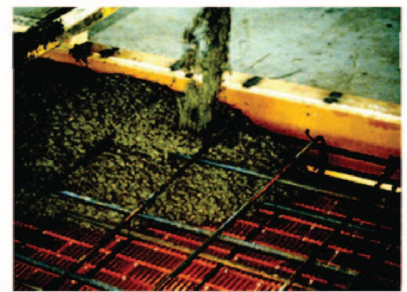

(d)

Figure 4. Estimate snap break veneer on a tilt-up concrete wall

velope. Figure 7(a) shows how this tilt-up panel is cast on the casting bed. Figure 7(d) shows how the panel is cast using the brick veneer as an embedded casting back. The task is to estimate the cost of the brick veneer, i.e. material and installation.

As stated in section 1.4, the PPQ, which is the brick material quantity in this case, looks easy to find by just adding areas of surface A and surface B and multiplying by the waste factor.

This gives us the square footage of the brick veneer of this panel. However, if the estimator knows how the contractor casts the tilt-up panel then the estimator would know this quantity is wrong.

The actual procedure of casting a brick veneer tilt panel is as follows:

1. The brick veneer is laid face-down on the casting bed.

2. Then the panel rebar is put on top of the brick veneer.

3 . The concrete is poured on the back of brick veneer.

4. The panel is tilted up and put it in its place.

In this process the brick veneer is embedded by the gravity of the concrete. However, the brick veneer of the B side of this panel as shown in Figure 4(c) cannot be installed the same way because the form board of the panel on the B side cannot hold the brick veneer in its place during the pouring of concrete. So the brick veneer of surface B must be installed later on after the panel is tilt up and put in place.

Because of this detailed tilt panel construction method, the installation cost and waste factors of surface B are significantly higher than those of surface A. So in order to get the correct cost of the veneer the estimator has to calculate the A area and the B area separately and apply their corresponding waste factors and unit installation cost separately. In this case both the A area and the B area are PCQ, which is determined by this particular tilt panel construction method and job condition. 


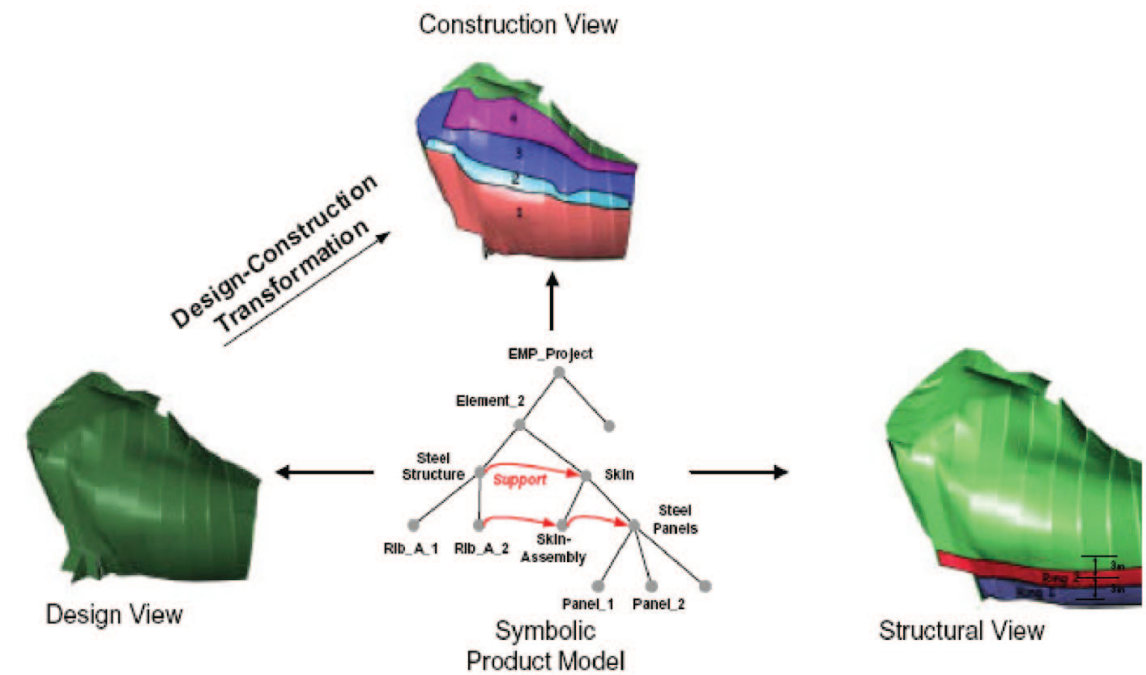

Figure 5. Multi-dimensional example of a building component [1]

This example illustrates how the quantities are broken down into small pieces because of the impact of a particular construction method and a different unit price is applied to each piece based on their different installation methods. Without knowing the trade specific knowledge, it is unrealistic to expect one to estimate the right quantities and the right cost especially for the PCQ and PCC in this example.

\subsection{Concept of Multi-dimensional Construction Views/Level of Details}

Buildings are very complex and unique: no two buildings are the same in the world. One project could include underground utilities, concrete products, a parking garage, elevators, boilers, chillers, a helicopter platform, sculptures, swimming pools, roller coaster etc. Very few if any products in the world have so broad a scope of works.

The diversity of the building project participants reflects the degree of the building's complexity and uniqueness. Since there are so many participants from different backgrounds and with different interests in every building project, it is very natural that each participant has their own view of the project. Figure 5 shows a multi-view example of an actual building component.

Construction management is about quantity and process management. When it comes to construction quantities, every project participant has specific quantities they are interested in, which reflect their specific construction information access needs. These quantities may not have the same level of details. 


\section{Conclusions}

In summary, although the current BIM models and its implementations have improved their capacity of accommodating the construction management requirements, the limitations still exist.

The fundamental remaining question is that how to create a construction data retrieval application using the current $3 \mathrm{D}$ visualization applications to reflect the contractors' perspectives.

It's the authors' view that the solution will rely on the more mature interpretation tools of the current 3D semantic data model. These interpretation tools shall address the particular trades' perspectives.

\section{References}

1. Akbas, R., and M. Fischer (1999). Examples of product model transformations in construction. In: M.A. Lacasse and D.J. Vanier (editors). Durability of Building Materials and Components 8. Institute for Research in Construction, Ottawa, Ontario, Canada, pp. 2,737-2,746.

2. ArchiCAD (2007). http:/ / www.graphisoft.com/products/archicad

3. AutoDesk Revit (2007). http:/ / revit.downloads.autodesk.com

4. IFC (2006). http:// www.iai-international.org/index.html

5. Issa, R., I. Flood and W. O'Brien (editors) (2003). 4D CAD and Visualization in Construction: Developments and Applications. A.A. Balkema, Lisse, The Netherlands.

6. O'Brien, W., R. Issa, Z. Shen and H. Xie (2004). Configurable environments: a vision for future project information technologies. In: S. Kazi (editor). Knowledge Management in the Construction Industry: A Socio-technical Perspective, pp. 339-358. Idea Group, Hershey, Pennsylvania, USA.

7. Rivard, H. (2000). A survey on the impact of information technology on the Canadian architecture, engineering and construction industry. ITcon 5: 37-56. 